\title{
Numerical Model of Ultra-High Molecular Weight Polyethylene Abrasive Wear Tests
}

\section{Tomas De la Mora Ramírez ${ }^{1,2 *}$, Isaías Hilerio Cruz¹, Marco Antonio Doñu Ruiz ${ }^{3}$, Noé López Perrusquia ${ }^{3}$, David García Bustos ${ }^{4}$, Martín Flores Martínez ${ }^{4}$}

\author{
${ }^{1}$ Autonomous Metropolitan University, Azcapotzalco Unit, Azcapotzalco, Mexico City, Mexico \\ ${ }^{2}$ Science and Engineering of Materials, Technological of Studies of Jocotitlán, Jocotitlán State of Mexico, Mexico \\ ${ }^{3}$ Group of Materials Science and Engineering, Polytechnic University of the Valley of Mexico, Tultitlán, \\ Mariano Escobedo, Mexico \\ ${ }^{4}$ University of Guadalajara, University Center of Exact Sciences and Engineering, Guadalajara, México \\ Email: ^tomas.delamora@tesjo.edu.mx, ihc@azc.uam.mx, marckdr_69@hotmail.com, noeperrusquia@hotmail.com, \\ edgb007@hotmail.com,martin.flores@cucei.udg.mx
}

How to cite this paper: De la Mora Ramírez, T., Hilerio Cruz, I., Doñu Ruiz, M.A., López Perrusquia, N., García Bustos, D. and Flores Martínez, M. (2020) Numerical Model of Ultra-High Molecular Weight Polyethylene Abrasive Wear Tests. Modeling and Numerical Simulation of Material Science, 10, 1-14.

https://doi.org/10.4236/mnsms.2020.101001

Received: August 31, 2019

Accepted: December 3, 2019

Published: December 6, 2019

Copyright (๑) 2020 by author(s) and Scientific Research Publishing Inc. This work is licensed under the Creative Commons Attribution International License (CC BY 4.0).

http://creativecommons.org/licenses/by/4.0/ (c) (i) Open Access

\begin{abstract}
Ultra-high molecular weight polyethylene (UHMWPE) has been used in orthopedics as one of the materials for artificial joints in knee, hip and spine prostheses, most of the implanted joints are designed so that the metal of the prosthesis is articulate against a polymeric material, however the main problems is the average life time of the UHMWPE due to wear, and the particles generated by the friction of the metal on the articulation of the polymer are the most common inducer of osteolysis, generating a loosening of the implant leading to an imminent failure resulting in the total replacement of the prosthesis. In this investigation a numerical model of abrasive wear was made using the classic Archard wear equation applied to dynamic simulation of finite element analysis (FEA) of the micro-abrasion test using a subroutine written in Fortran language linked to the finite element software to predict the rate of wear. The results of the numerical model were compared with tests of abrasive wear in the laboratory, obtaining a margin of error below $5 \%$, concluding that the numerical model is feasible for the prediction of the rate of wear and could be applied in knowing the life cycle of joint prostheses or for the tribological analysis in industrial machinery or cutting tools. The wear coefficient $(K)$ was obtained from the grinding tests depending on the depth of stroke of the crater, which was analyzed by $3 \mathrm{D}$ profilometry to obtain the wear rate and the wear constant.
\end{abstract}

\section{Keywords}

Abrasive Wear, Finite Element, Numerical Wear Model, UHMWPE 


\section{Introduction}

Wear by contact between surfaces is one of the main causes in the reduction of the life time of the components in industrial machinery, tools and specifically in biomedical parts [1].

Wear is a process that occurs on the surfaces of solid bodies due to the friction of another body; modifying the macro and micro surface geometry of the structure and the properties of the surface layers; with or without loss of material [2].

In the work, abrasive wear is simulated; this happens when a surface is damaged by the introduction of a material harder than the base material. The harder material is introduced into the system in the form of particles, which enter externally or can be generated internally by oxidation or other chemical processes.

Previous studies of problems related to wear in knee prostheses suggest that wear debris is capable of initiating inflammatory responses, causing periprosthetic osteolysis and bone resorption at the implant-bone interface [3]. These responses can induce pain and loosening of the implant which leads to revision surgeries and in most cases the total change of the prosthesis.

The biological response to particles in suspension depends on several factors, such as: the number of waste particles of wear, size and shape, the morphology of the wear surface and the speed at which they accumulate in the periprosthetic tissues [4]. Therefore, one of the applications of the tribological tests is to serve as an effective preclinical tool to investigate the wear characteristics of the devices and improve the performance of the implant after surgery [5].

In the last decade, bio-tribological simulations have been investigated in the areas of knee implants [6], including simulations of finite element models by computer, and mechanical tests.

Ali M. Alsamhan in his research focused on the control of the duration of life of the artificial knee, with the optimal thickness variable of the polyethylene layer (the commercially available thicknesses are 8,9 and $10 \mathrm{~mm}$ ), elaborated a 3D digital model of the prosthesis, and then performed stress concentration analysis in the contact area between the tibial insert of UHMWPE and the metal material of the prosthesis. Predict the maximum effort of Von Mises in the area determining that the thickness of $10 \mathrm{~mm}$ is the most advisable to take into account by orthopedist that most times they do not find a decision parameter to select the thickness [7].

Volodymyr Pakhaliuk and Alexander Polyakov in their article published in 2015 , analyzed the wear of the spherical joint of the total hip prosthesis in the acetabular cup of UHMWPE in combination with the metal by means of finite elements, used a model of the classic equation Archard-Lancaster to predict wear. Compared the results obtained from the numerical analysis, the mathematical model and the data obtained from the laboratory tests on the polymeric material. Obtained very close results with the three criteria, showing that the developed method is a very useful tool for the application of the most accurate classification analysis of the design, allowing to reduce the use of expensive ex- 
perimental studies using physical simulators [8].

In 2014 Marcin Nabrdalik presented an article of numerical analysis of the stress analysis in the wear zones of the knee joint, working with the geometric modification of the tibial insert suggesting a spherical insert [9].

Marjan Bahraminasab used a biomaterial for the femoral component of the total knee replacement of NiTi material with shape memory alloy to analyze the contact with the joint, the Von Mises stress distribution of the femoral bone was evaluated through the methods of elements finite. Compare results with commercial alloy materials: $\mathrm{Cr}-\mathrm{Co}$ and $\mathrm{Ti}-6 \mathrm{Al}-4 \mathrm{~V}$. The results obtained that the NiTi indicates that it reduces the effort eliminating the shielding effect that originates the loosening of the prosthesis in the implant. However, the study has its limitations, the geometry of the implant was not modified and the studies were limited to the condition of static load and not in real conditions of loading in progress [10].

Hongtao Liu performed tribological analyzes of ultra high molecular weight polyethylene self-reinforced with UHMWPE powder of high strength and high modulus of fiber and hot pressing, an M-2000 tester was used. With the previous methodology, the coefficient of friction and wear was reduced in comparison with pure UHMWPE [11].

Feng Liu used a computational model for the prediction of wear in hip joint prostheses, it is simulated full cycle to reproduce the wear of the physiological bearing in vitro [12].

Bernardo Innocenti developed and validated a finite element methodology to predict the wear of ultra high molecular weight polyethylene. The wear model was developed applying an experimental roll-on-plane wear test. Subsequently, the model was developed to predict patellofemoral wear under the same contour conditions of the experimental tests. The developed model assumes importance for its use in the development in the orthopedic clinical field in order to help patients to predict after a knee surgery, in addition to improve the materials of the tibial inserts [13].

Jonathan Netter used a computational model to predict knee wear, generated in vitro under different conditions. We used reverse engineering with finite element analysis to generate two different designs of total knee prosthesis to determine the wear factors in the polyethylene material [14].

Rodríguez Martínez R. and collaborators developed a simple methodology for modeling and analyzing using FEM of the contact areas in the metal femoral insert and the tibial insert UHMWPE where the stress values are higher, according to the normalized walking cycle. They solved the geometric modeling of the bodies that are in contact through computerized axial tomography (CAT) of the bones, processed in a CAD system for the construction of the solid model.

Ali M. and Marcin Nabradalik only Von Mises concentration was analyzed to perform thickness modification and topological modification depending on the patient's weight. 
Marjan Bahraminasab studied the geometry of the implant and the studies were limited to the static loading condition and not under actual loading conditions in progress or dynamic simulation. The numerical model of Pakhaliuk and Polyakov presents excellent results, however, it is very limited only to the acetabular cup of the hip prosthesis without being flexible for other applications since only contact pressure was used to determine the areas of greatest volume loss of wear Bernardo Innocenti similar to the numerical model of Pakhaliuk and Polyakov are the most complete to use in the prediction of wear, however they have little flexibility because they used only as a parameter the contact pressure and cannot be extended to other applications. Again Feng Liu performed the simulation of wear limited to the hip prosthesis without being flexible for application in other joints. Hongtao Liu used only the experimental part in a physical simulator for knee prostheses. Jonathan Netter predicted wear through a computational model and compared it with in vitro tests without using programming. The model is very rigid and, like others, has no flexibility.

Rodríguez, similar to other authors, is only based on the concentration of efforts for topological modification of the knee prosthesis with the innovation of the development of geometry by axial tomography [15].

The present investigation refers to the insert in knee and hip joint prostheses, of UHMWEP material and the dynamic simulation in finite element of the abrasive wear mechanism in squat activity condition, a Fortran program of finite element (FE) was created based on Archard's wear law [16]. An adaptive mesh technique was used to simulate wear on the polymer core of the implant. Adaptive meshing captures changes in the articulation surface as the surface wears and deforms. The FE analysis was performed based on the existing wear standards and then compared with simulations performed experimentally. The wear coefficient derived from experimental data was used to calibrate the numerical model.

The difference of our project to the previous ones is that Fortran language programming will be used to predict the wear rate, where the variables to be used will be: sliding distance, normal load and the wear constant. Thus the simulation program could be applied to various types of joint prostheses or extended to parts of industrial machinery.

The literature review concludes that numerical analysis is a powerful tool for modeling and obtaining reliable results quickly, establishing a new methodology to develop implants based on the most common use in health institutions to produce models compatible with the anthropometry of Mexican race.

\section{Methodology}

The most commonly used wear model is Archard. This model has been used by Molinari [17], Podra [18], Cantizano [19], Agelet [20], Hegadekatte [21]. In the implementation of the wear simulation, the Archard wear model proposal has been selected to simulate the friction wear that occurs in the contacts between 
polyethylene and the grade 5 titanium alloy (Ti6Al4V) in the knee prosthesis.

The Archard wear model is given by Equation (1)

$$
\frac{V}{A * s}=\frac{K}{H} * \frac{F}{A}
$$

where:

$V$ : volume of wear;

$A$ : apparent area subject to wear;

$F$. normal force exerted on the specimen;

s. sliding distance;

$K:$ is the wear coefficient of Archard (which is obtained experimentally);

$H:$ it is the hardness of the softest material.

By design, the wear depth $h$ is more convenient than the wear volume $V$. If we define the depth, $h=V / A$, and the contact pressure $P=F / A$. Equation (1) expressed in terms of depth of wear is as follows.

$$
h=\frac{K}{H} * s * P
$$

The wear coefficient $K$ was taken from the results of the experimental tests carried out in the laboratory, by definition the Archard wear coefficient, is the fraction of the roughnesses that produce the wear particles, the ratio between the worn volume and the deformed volume [22].

If both sides of Equation (2) are divided by the sliding time, we obtain the wear rate $W$.

$$
\frac{h}{t}=\frac{K}{H} * \frac{s}{t} * P
$$

where:

$\frac{h}{t}=w:$ it's the wear rate;

$\frac{s}{t}:$ it is the sliding speed;

$P:$ is the contact pressure.

Equation (3) is the classic wear model developed by F. Archard in 1953 [23], it does not consider the hardness $H$ of the material, important for the wear between metal surfaces, but it is not an important factor for the wear of polymers [24].

The wear equation developed by Archard was used by a subroutine of finite element software. The subroutine called UMESHMOTION, defines the movement of nodes in an adaptive mesh domain. The magnitude of movement of these nodes is controlled by Archard's wear law. UMESHMOTION is a subroutine written in fortran language, which has the following configuration and structure provided by the finite element software subroutine library.

SUBROUTINEUMESHMOTION (UREF, ULOCAL, NODE, NNDOF) \& LNODETYPE, ALOCAL, NDIM, TIME, DTIME, PNEWDT, \& KSTEP, KINC, 


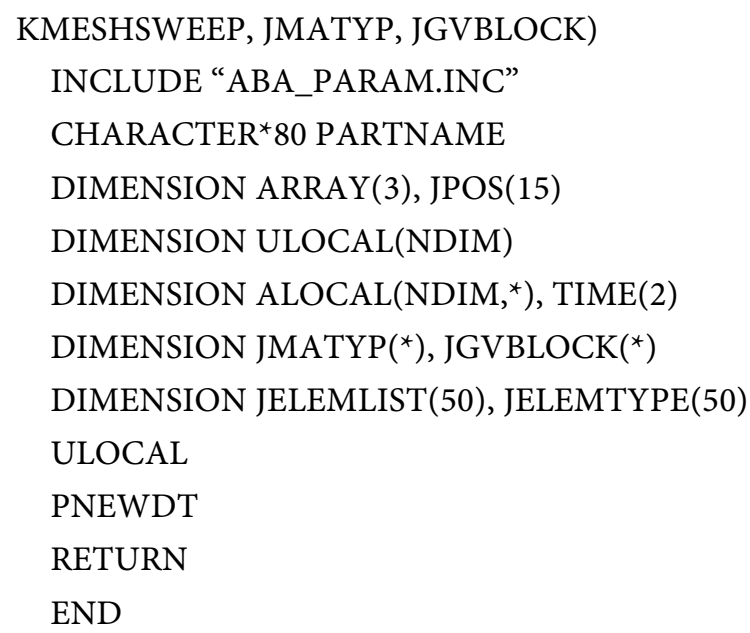

The main variables used for the analysis of wear are the following:

- CSLIP, contact slip variable provides information about the sliding distance relative to the tangential movement of the nodes at the contact interface between the surfaces.

- CPRESS, is the variable of the normal force of contact pressure between the surfaces.

- CSHEAR, friction cutting tension variable, which defines an abrasion contact.

The following flow diagram in Figure 1 shows the steps incorporated into the wear program written in Fortran code.

Equation (3), $s / t$ is the relative slip distance, this parameter is calculated in the model as the tangential movement of the nodes in the contact interface, is CSLIP. Its maximum value is calculated from its CSLIP1 and CSLIP2 components as follows:

$$
\mathrm{CSLIP}=\frac{s}{t}=\left\{(\mathrm{CSLIP} 1)^{2}+(\mathrm{CSLIP} 2)^{2}\right\}^{\frac{1}{2}}
$$

The structure of the program developed in Fortran during the simulation of the abrasive wear test is as follows.

The structure generated by the UMESMOTION subroutine integrates the value of the wear constant $K$, obtained in the abrasive wear tests in the laboratory, this constant changes depending on the conditions of the test, load, sliding distance

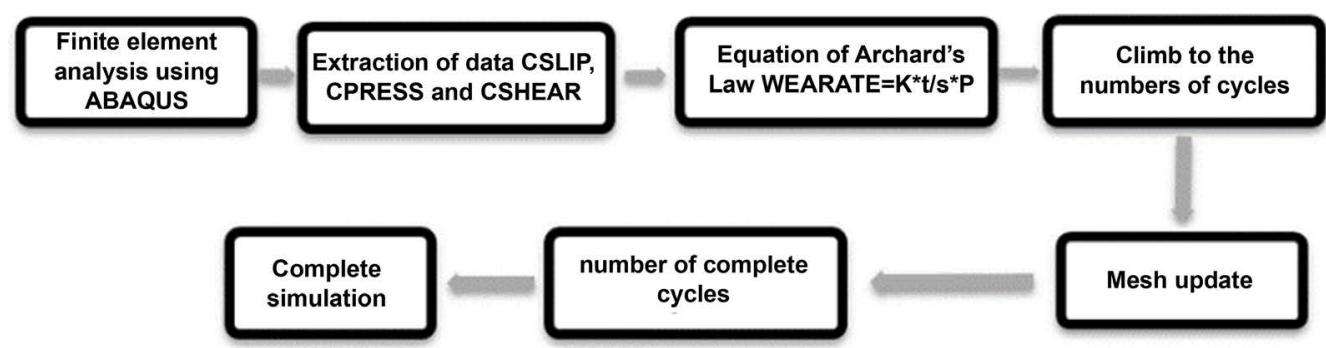

Figure 1. Flowchart representing the steps involved in the custom UMESHMOTION wear code to simulate the wear of a micro-abrasion test. 
or number of cycles and concentration of the percentage of the abrasive liquid. The program also integrates the variable $N$ that defines the number of cycles used in the tests, the data were entered into the program as radians, 1000 cycles equals $6283.18 \mathrm{rad}, 2000$ cycles at 12,566.57 rad and 4000 cycles at 25,132.74. The Nodesmax parameter indicates the value of the node where the CSLIP, CPRESS and CSHEAR values will be obtained.

In the program, the output variables are added to be applied in the Archard equation and obtain the final values depending on the number of iterations as a consequence of the number of cycles or sliding distance. The output variables are: the CPRESS which indicates the contact pressure between surfaces, updating its value depending on the location of the selected node on the slave surface, which will exhibit the wear, CSHEAR1 which indicates the cutting tension force due to the friction in the local direction 1 (direction perpendicular to the application of normal force on the $X$ axis) and CSHEAR2 indicating the shear stress due to friction in the local direction 2 (direction perpendicular to the application of force normal on the $Z$ axis).

The application of the Archard wear equation is used with the data obtained from the variables CSLIP, CPRESS and CSHEAR. With this part of the program the UMESHMOTION subroutine is finished.

The link between the program developed in fortran language and the finite element software is made through the integrated interface in the program.

With the use of the subroutine the Lagrangian-Eulerian adaptive mesh (ALE) technique was used, this tool allows to maintain a high quality mesh throughout the analysis, despite the great deformation or loss of material, by allowing the mesh move independently of the rest of the material. The adaptive mesh finite element software is designed to be used in acoustic domains and to model the effects of ablation or wear of materials, such as what was done.

The wear analysis by the finite element method created was based on the configuration of the micro abrasive wear experiment performed in the laboratory.

A static analysis was used for the simulation of wear, a sphere model, simple flat test tube was created to simulate the micro-abrasion test as shown in Figure 2.

The wear program was written based on the geometrical configuration of the machine, contact surfaces and nodes involved.

The contact surface of the sphere was defined as a hard contact interaction, due to the mechanical characteristics of the material; the polymer surface was assigned as the slave surface, and the bottom of the sphere was assigned as the master surface. The slave-master parameters are characteristic in the interaction of surfaces in finite element software.

Wear was calculated for the central part of the polymer specimen and the values of CSLIP (contact slip variable available finite element software) as well as CPRESS (contact pressure variable available finite element software) were obtained from the nodes of the polymeric surface. It must be taken into account 


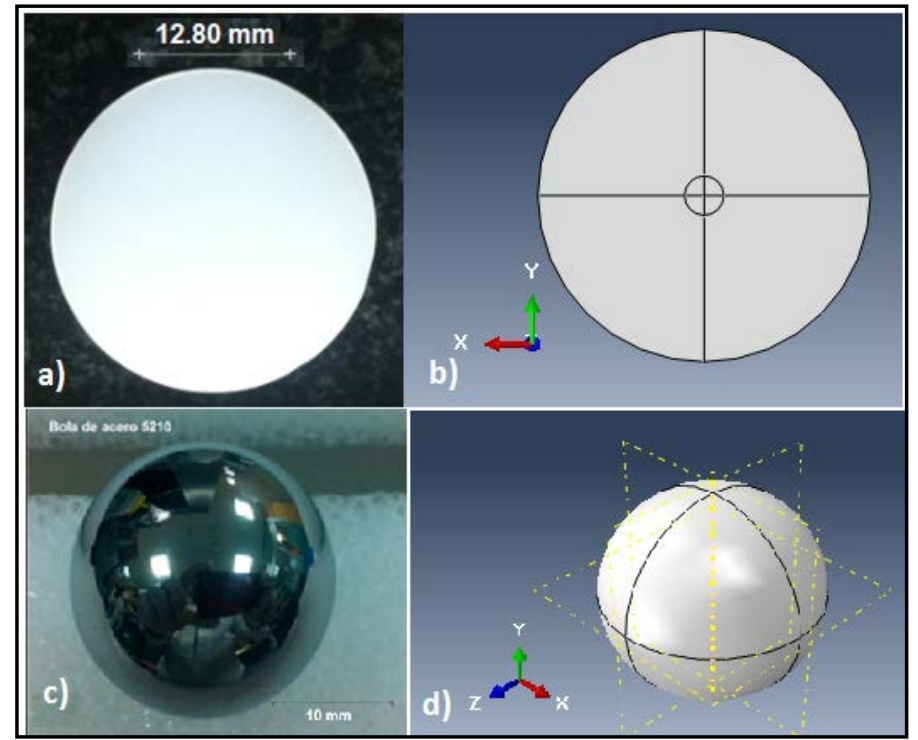

Figure 2. UHMWPE cylindrical test piece and 52100 steel ball used in the micro abrasion test. (a) Polyethylene specimen; (b) 3D model of the specimen; (c) 52100 steel ball; and (d) 3D model of the sphere.

that CSLIP (contact slip) can only be obtained from a slave surface. Therefore, if we need to model the wear on an articulated surface, that surface must be assigned as the SLAVE surface with respect to the other component to extract the CSLIP values.

It is important to mention that for the adaptive meshing it is essential to model the wear surface as C3D8 elements. In addition, non-linear geometries should be used.

These parameters are used together in the Archard wear law equation applied in the program in Fortran language, being finally as follows:

$$
\text { Wearate }=h=K * \text { CSLIP } * \text { CPRESS }
$$

Another used subroutine that complements the previous one is the UFIELD was written to show the wear contour as a function of the linear cumulative depth (hs) of the model, which was calculated in each increment of Equation (5).

\section{Results}

Table 1 shows the depth values of footprint, volume, wear rate and the constant $K$, which is the coefficient of wear obtained by the Archard wear equations [23].

The results obtained in Table 1 of the experimental micro-abrasion tests in the condition of $5 \mathrm{~N}-1000$ have a wear depth of $0.0115 \pm 2.20 \mathrm{e}-5 \mathrm{~mm}$, the results of the test in the simulation, the wear depth linear is $h s=0.0118 \mathrm{~mm}$. This linear wear depth was calculated as a function of the magnitude of the total displacement Uy. Obtaining a depth of wear in the direction of " $y$ " (see Figure 3).

Equation (6) is used to obtain the depth of linear wear in the crater, it is based on the diameter of the rotating ball, and the diameter of the footprint left on the test specimen, depending on the\% of abrasive liquid (slurry). 
Table 1. Results obtained from the micro-abrasion test of wear volume and wear coefficient.

\begin{tabular}{cccc}
\hline Specimen & $\begin{array}{c}\text { Wear depth } \\
h s[\mathrm{~mm}]\end{array}$ & $\begin{array}{c}\text { Volume Hutchings } \\
{\left[\mathrm{mm}^{3}\right]}\end{array}$ & $\begin{array}{c}\text { Wear coefficient } \\
k\left[\mathrm{~mm}^{3} / \mathrm{Nm}\right]\end{array}$ \\
\hline $5 \mathrm{~N}-1000$ & $0.0115 \pm 2.20 \mathrm{e}-5$ & $0.0005283 \pm 2.0 \mathrm{e}-6$ & $2.51 \mathrm{e}-9 \pm 9.65 \mathrm{e}-8$ \\
$5 \mathrm{~N}-2000$ & $0.014 \pm 6.61 \mathrm{e}-5$ & $0.0004697 \pm 4.2 \mathrm{e}-6$ & $1.19 \mathrm{e}-9 \pm 7.8 \mathrm{e}-7$ \\
$5 \mathrm{~N}-4000$ & $0.032 \pm 7.8 \mathrm{e}-5$ & $0.003264 \pm 1.52 \mathrm{e}-5$ & $3.92 \mathrm{e}-9 \pm 2.3 \mathrm{e}-7$ \\
\hline
\end{tabular}

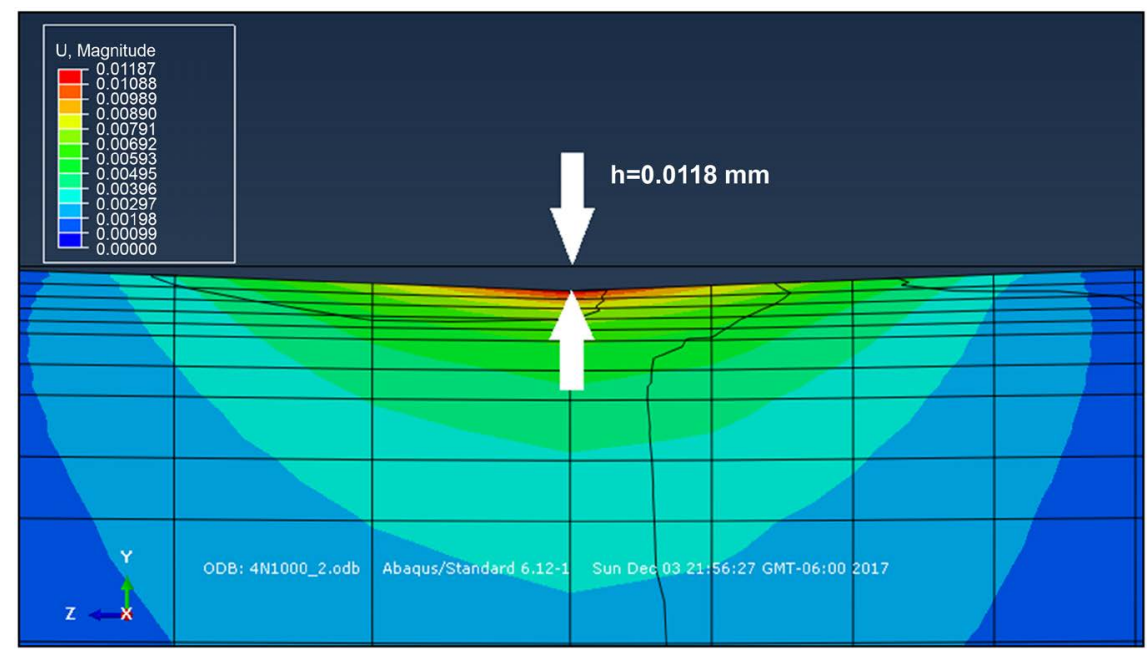

Figure 3. Displacement, magnitude in the direction of $Y$, which is the wear depth of the simulation under conditions of $5 \mathrm{~N}-1000$.

$$
h=\frac{D}{2}-\sqrt{\left(\frac{D}{2}\right)^{2}-\left(\frac{d}{2}\right)^{2}}
$$

The simulations that were carried out in finite element were of the tests in the conditions of $5 \mathrm{~N}-1000$ and $5 \mathrm{~N}-4000$ to take into consideration the minimum and maximum number of cycles of the test in the micro-abrasion tribometer. Table 2 shows the summary of the results of the wear depths obtained in the experimental and simulated tests by means of the link of the Fortran-software program.

Table 2 shows the wear values of the simulation which are very close to those obtained in laboratory tests, resulting in a margin of error of $1.69 \%$.

The margin of error obtained by the comparison between laboratory tests and the virtual analysis of the wear depth is less than $5 \%$, so the wear prediction program is validated. The wear depth $(\mathrm{mm})$ was plotted on the $Y$ axis, and the sliding distance $(\mathrm{mm})$ was measured on the $X$ axis.

Graphically (Figure 4) observes a similar trend in experimental wear points and by finite element analysis (FEA).

The rate of wear in the finite element analysis program is given by the variable VOLC, which is the change in the volume of a set of elements during adaptive meshing, specifically in the nodes that are in contact with the ball. wear (in the specific case of our geometry is the node located in set 88) (Figure 5). VOLC is 
Table 2. Summary of wear depth results in the different test conditions.

\begin{tabular}{cccc}
\hline $\begin{array}{c}\text { Condition of the } \\
\text { specimen }\end{array}$ & $\begin{array}{c}\text { Experimental wear depth } \\
h[\mathrm{~mm}]\end{array}$ & $\begin{array}{c}\text { Wear depth simulation } \\
h[\mathrm{~mm}]\end{array}$ & $\begin{array}{c}\text { Error range } \\
\%\end{array}$ \\
\hline $5 \mathrm{~N}-1000$ & $0.0115 \pm 2.7 \mathrm{e}-5$ & 0.0118 & 3.36 \\
$5 \mathrm{~N}-4000$ & $0.0320 \pm 7.8 \mathrm{e}-5$ & 0.0310 & 3.12 \\
\hline
\end{tabular}

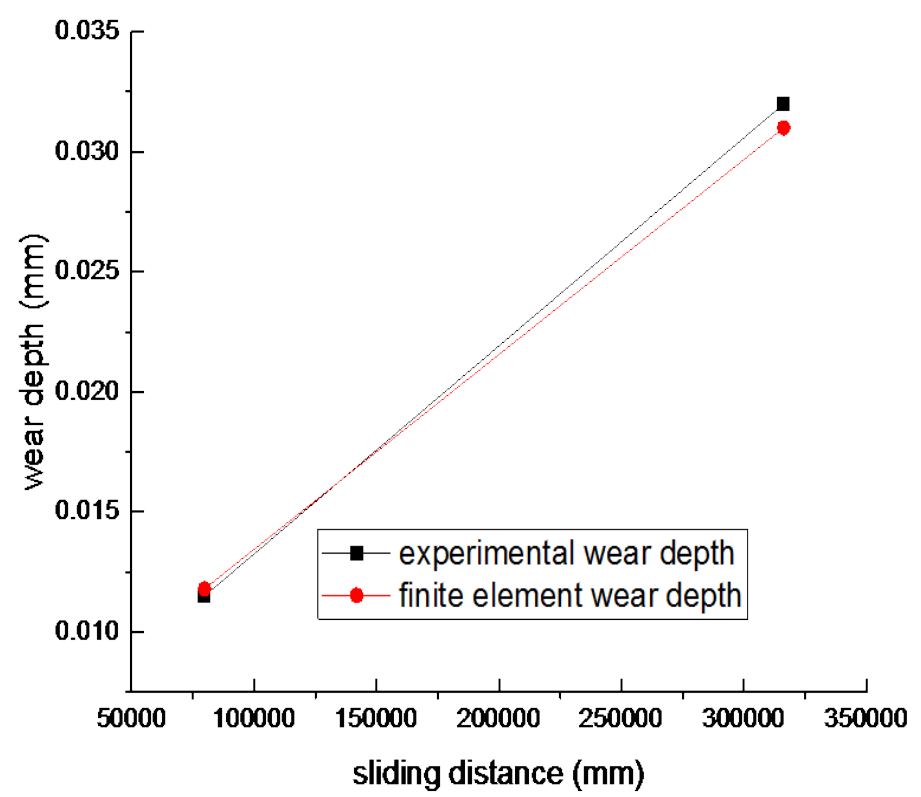

Figure 4. Graph of depth of wear with distance traveled.

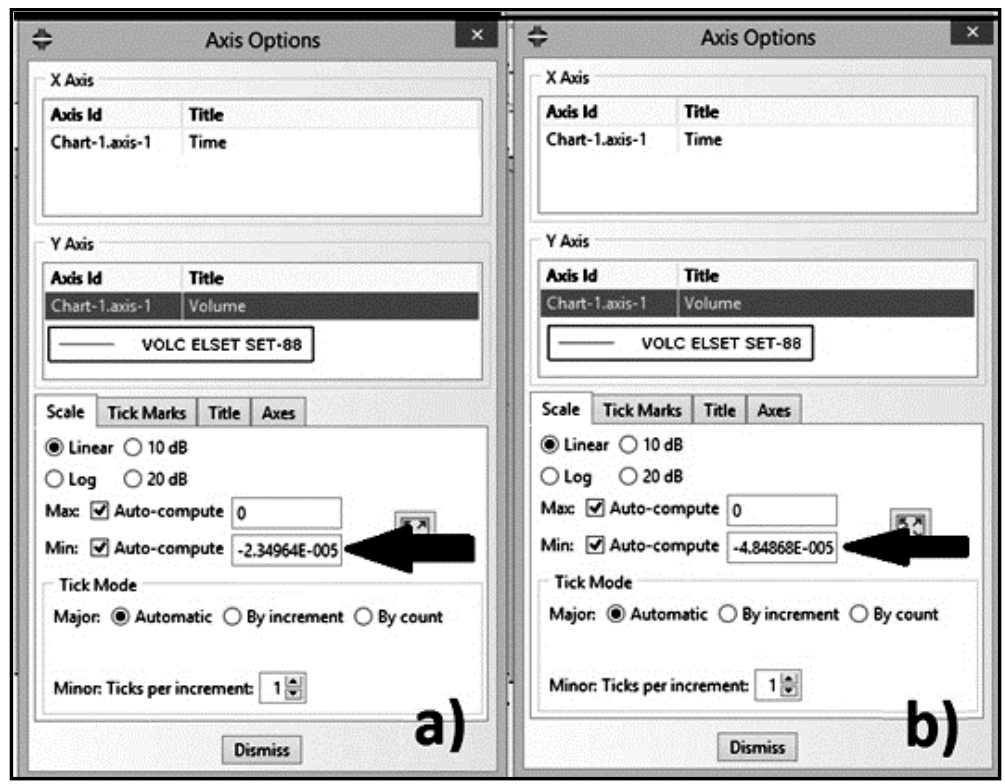

Figure 5. Results of the variable VOLC that gives us the rate of wear $(w)$ in the software with the conditions: (a) $5 \mathrm{~N}-1000$ and (b) $5 \mathrm{~N}-4000$.

in the option of output variables of the History Output, which collects the information of the output variables during the total time that the test lasts. For 
example 25 minutes for the test of 1000 cycles.

The result obtained in the condition of $5 \mathrm{~N}-1000$ with the program developed in Fortran and linked to the finite element software, the wear rate gives a value of Ws $=2.35 \mathrm{e}-5 \mathrm{~mm}^{3} / \mathrm{Nm}$ and the experimental data Wexpe $=2.52 \mathrm{e}-5$ $\mathrm{mm}^{3} / \mathrm{Nm}$, with a margin of error of $6.74 \%$. Table 3 gives us the comparison of experimental results and the simulation program in the different test conditions.

The results of Table 3 indicate that at cycles greater than 4000 cycles the error decreases considerably, this as a consequence of the fact that the greater the number of cycles, the test stabilizes as a consequence of the roughness of the ball and the test piece, as well as the amount of abrasive substance that is in contact between the ball and the specimen in the experimental test (Contact of three bodies).

The results of the experimental wear rate and that of the FEA program were plotted (Figure 6) taking the $Y$ axis $\left(\mathrm{mm}^{3} / \mathrm{Nm}\right)$ as the wear rate and the $X$ axis (in $\mathrm{min}$ ) as the slip time.

\section{Discussion}

The results of the program are based on the data obtained from the depth of the wear crater, the abrasion test experiments were conducted under a given set of input conditions at 1000 and 4000 cycles, taking into consideration the minimum

Table 3. Wear rate in different conditions.

\begin{tabular}{cccc}
\hline Specimen & $\begin{array}{c}\text { Rate of experimental wear } \\
W_{\exp }\left[\mathrm{mm}^{3} / \mathrm{Nm}\right]\end{array}$ & $\begin{array}{c}\text { Simulated wear rate } \\
W_{s}\left[\mathrm{~mm}^{3} / \mathrm{Nm}\right]\end{array}$ & $\begin{array}{c}\text { Error range } \\
\%\end{array}$ \\
\hline $5 \mathrm{~N}-1000$ & $2.52 \mathrm{E}-05$ & $2.35 \mathrm{E}-05$ & 6.74 \\
$5 \mathrm{~N}-4000$ & $5.00 \mathrm{E}-05$ & $4.85 \mathrm{E}-05$ & 3 \\
\hline
\end{tabular}

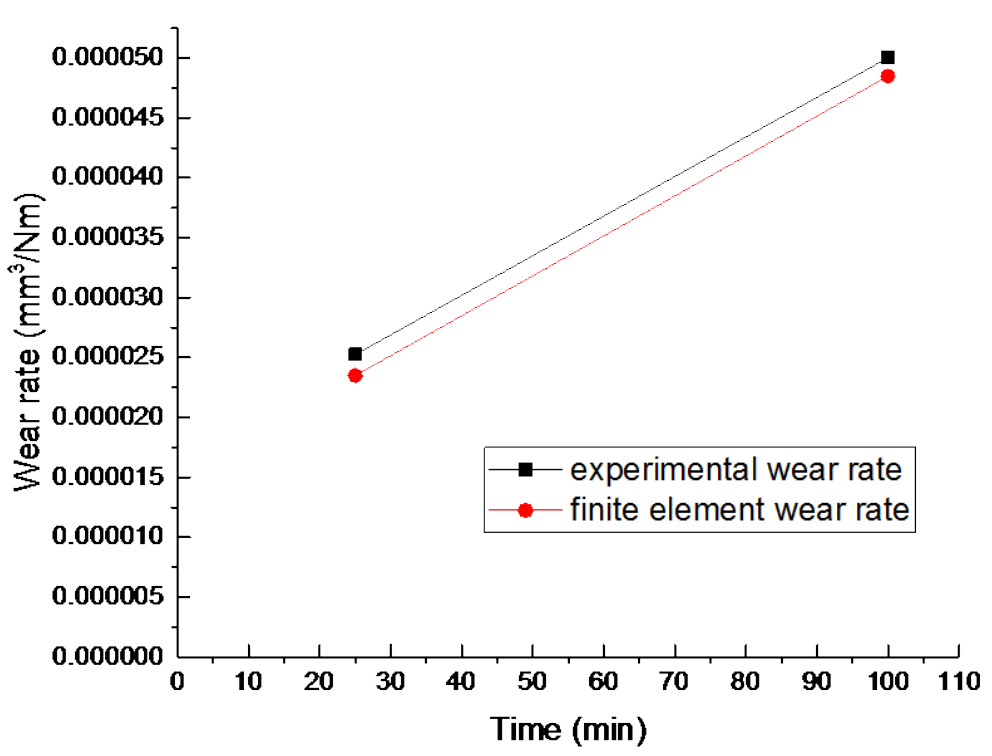

Figure 6. Lines of experimental wear rate and simulated by finite element in condition $5 \mathrm{~N}-1000$. 
and maximum cycles in laboratory, obtaining the wear coefficient of Archard $K$, which has been used as data to be introduced to the program. The wear factor is found in a wide range of values depending on the lubricant used or if the test is dry and the surface roughness of the bodies that interact [24]. In the experimental results the volume of wear is very similar to the 1000 and 2000 so the simulation in FEA was performed in the conditions of minimum and maximum cycles. The coefficient of friction $K$ decreases by $50 \%$ when going to the 2000 cycles as shown in Table 1. Although there is a difference in the value of the depth $h s$ between the cycles 1000 and 2000 the volume of wear does not change much. At 4000 cycles, the variables of depth, volume and coefficient of wear increase exponentially, especially the volume of wear to $700 \%$ with respect to the value of the 2000 cycles. The displacements that simulate the depths in low and high cycles, the values are very similar to the experimental results, the error range of the simulated discarding rate increases in low cycles. The program in Fortran language was developed based on the configuration of the experimental micro-abrasion test machine, taking as a fundamental part the classic Archard wear equation and the experimentally obtained wear constant. The wear rate obtained are very close to those made in the laboratory, so the program could be used to predict the wear of different types of materials by modifying the modulus of elasticity, the wear constant and the number of cycles desired.

\section{Conclusion}

The program developed in Fortran code based on Archard's law for the calculation of the wear rate at different test distances was validated with the results obtained from the laboratory micro-abrasion tests at cycles of 1000 and 4000, obtaining margin of error below 5\%. The value used in the wear coefficient program $(K)$ was obtained from abrasive tests based on the depth of the wear footprint; the program predicts the wear rate with the use of the constants entered directly as they are: normal load, sliding distance (number of cycles) and indirectly the percentage of concentration of the abrasive liquid (slurry). Therefore, the results in the Fortran language program agree that the greater the number of cycles, the less the margin of error with respect to laboratory experimentation. To improve the reliability of the program, it is recommended that for future work, laboratory tests are performed at cycles below 500 and compared with those obtained in the program, which can be concluded that the numerical mod$\mathrm{el}$ is feasible for the prediction of the rate of wear and could be applied in predictions for obtaining the life cycle of joint prostheses or for the tribological analysis in industrial machinery or cutting tools.

\section{Acknowledgements}

Our thanks to CONACYT for the scholarship to carry out the Doctorate project, the Doctorate in environmental science and engineering and materials from the Autonomous Metropolitan University (UAM), the University Center for Exact 
Sciences and Engineering of the University of Guadalajara (U of G), the BREAK FIX Trauma company in Mexico, for the material and use of the prosthesis for the research project and To the Technician of Superior Studies of Jocotitlan (TESJo) for the financing for the publication of the article.

\section{Conflicts of Interest}

The authors declare no conflicts of interest regarding the publication of this paper.

\section{References}

[1] Rodríguez, R., Urriolagoitia-Sosa, Torres, Ch., Hernández, L., Urriolagoitia-Calderón, G. and Carbajal, M. (2012) Development of an Experimental Apparatus for Testing Total Knee Prostheses Focused on Mexican Phenothype. International Journal of Physical Sciences, 7, 5779-5786.

[2] Tabor, B.Y. (1973) Fricción una introducción a la Tribología.

[3] Amstutz (1992) Mechanism and Clinical Significance of Wear Debris-Induced Osteolysis. Clinical Orthopaedics and Related Research, 276, 7-18.

https://doi.org/10.1097/00003086-199203000-00003

[4] Tipper (2006) Isolation and Characterization of UHMWPE Wear Particles Down to Ten Nanometers in Size from in Vitro Hip and Knee Joint Simulators. Journal of Biomedical Materials Research Part A, 78, 473-480.

https://doi.org/10.1002/jbm.a.30824

[5] Ingham (2000) Biological Reactions to Wear Debris in Total Joint Replacement. Journal of Engineering in Medicine, 214, 21-37.

https://doi.org/10.1243/0954411001535219

[6] Pal, S. (2008) Probabilistic Computational Modeling of Total Knee Replacement Wear. Wear, 264, 701-707. https://doi.org/10.1016/j.wear.2007.06.010

[7] Alsamhan, A.M. (2012) Rationale Analysis of Human Artificial Knee Replacements. Journal of King Saud University Engineering Sciences, 25, 49-54.

https://doi.org/10.1016/j.jksues.2011.12.002

[8] Pakhaliuk, V., Polyakov, A., Kalinin, M. and Kramar, V. (2015) Improving the Finite Element Simulation of Wear of Total Hip Prosthesis' Spherical Joint with the Polymeric Component. Procedia Engineering, 100, 539-548.

https://doi.org/10.1016/j.proeng.2015.01.401

[9] Nabrdalik, M. (2014) Use of the Finite Elements Method in the Analysis of Load of Polyethylene Inserts of Knee Joint Endoprosthesis. Journal of Applied Mathematics and Computational Mechanics, 13, 87-93. https://doi.org/10.17512/jamcm.2014.2.09

[10] Bahraminasaba, M. (2011) Finite Element Analysis of the Effect of Shape Memory Alloy on the Stress Distribution and Contact Pressure in Total Knee Replacement. Trends in Biomaterials and Artificial Organs, 25, 95-100. https://doi.org/10.1016/j.proeng.2015.01.401

[11] Liu, H.T., Liu, Y.H., Gao, J.P. and Yue, H.L. (2015) Tribological Properties of Self-Reinforced Ultra-High Molecular Weight Polyethylene Composites. Materials Express, 5, 146-152. https://doi.org/10.1166/mex.2015.1215

[12] Liu, F., Fisher, J. and Jin, Z.M. (2013) Effect of Motion Inputs on the Wear Prediction of Artificial Hip Joints. Tribology International, 63, 105-114. 
https://doi.org/10.1016/j.triboint.2012.05.029

[13] Innocenti, B., et al. (2014) Development and Validation of a Wear Model to Predict Polyethylene Wear in a Total Knee Arthroplasty: A Finite Element Analysis. Lubricants, 2, 193-205. https://doi.org/10.3390/lubricants2040193

[14] Netter, J., et al. (2015) Prediction of Wear in Crosslinked Polyethylene Unicompartmental Knee Arthroplasty. Lubricants, 3, 381-393. https://doi.org/10.3390/lubricants3020381

[15] Rodriguez, R., Urriolagoitia, G., Torres, Ch., Hernandez, L.H. and Martínez, I. (2013) On the Numerical Analysis of Contact Stresses in a Total Knee Replacement (TKR). Science and Information Conference, London, 7-9 October 2013, 197-201.

[16] Archard, J.F. and Hirst (1956) Wear of Metals under Unlubricated Conditions. Proceedings of the Royal Society of London Series A, Mathematical and Physical Sciences, 236, 410. https://doi.org/10.1098/rspa.1956.0144

[17] Molinari, J.F. (2001) Finite-Element Modeling of Dry Sliding Wear in Metal. Engineering Computations, 18, 592-601. https://doi.org/10.1108/00368790110407257

[18] Põdra, P. and Andersson, S. (1999) Simulating Sliding Wear with Finite Element Method. Tribology International, 32, 71-81.

https://doi.org/10.1016/S0301-679X(99)00012-2

[19] Cantizano, A., Carnicero, A. and Zavarise, G. (2002) Numerical Simulation of Wear-Mechanism Maps. Computational Materials Science, 25, 54-60. https://doi.org/10.1016/S0927-0256(02)00249-5

[20] Agelet De Saracibar, C. and Chiumenti, M. (1999) On the Numerical Modeling of Frictional Wear Phenomena. Computer Methods in Applied Mechanics and Engineering, 177, 401-426. https://doi.org/10.1016/S0045-7825(98)00390-9

[21] Hegadekatte, V., Huber, N. and Kraft, O. (2005) Finite Element Based Simulation of Dry Sliding Wear. Modelling and Simulation in Materials Science and Engineering, 13, 57-75. https://doi.org/10.1088/0965-0393/13/1/005

[22] Rigne, D.A. (1997) Comments on the Sliding Wear of Metals. Tribology International, 30, 361-367. https://doi.org/10.1016/S0301-679X(96)00065-5

[23] Archard, J. (1953) Contact and Rubbing of Flat Surfaces. Journal of Applied Physics, 24, 981-988. https://doi.org/10.1063/1.1721448

[24] Trezona, R.J. and Hutchings, I.M. (1999) Three-Body Abrasive Wear Testing of Soft Material. Wear, 233-235, 209-221. https://doi.org/10.1016/S0043-1648(99)00183-0 